\title{
HIV|AIDS Good News and Bad News
}

\author{
Masoud Mardani ${ }^{1, *}$ \\ ${ }^{1}$ Infectious Diseases and Tropical Medicine Research Center, Shahid Beheshti University of Medical Sciences, Tehran, IR Iran \\ ${ }^{*}$ Corresponding author: Masoud Mardani, Infectious Diseases and Tropical Medicine Research Center, Shahid Beheshti University of Medical Sciences, Tehran, IR Iran. Tel: +98- \\ 2122439963-8, Fax: +98-2122439964, E-mail: drmasoudmardani@yahoo.com
}

Received: September 3, 2014; Accepted: September 17, 2014

Keywords:HIV; Treatment; Infection

Thirty years into the HIV epidemic, it is time of celebration for successes in dealing with HIV combination antiretroviral therapy (CART), effective prevention of mother to child transmission (PMTCT), treatment as prevention, and effective opportunistic infections prophylaxis, which has been resulted increasing life expectancy of persons living with HIV (1). Moreover with the tools we have to prevent (pre exposure prophylaxis, condoms, circumcision) and treat HIV, certain groups have experienced declines in HIV incidence (2). Now days, most experts agree that HIV infection is no longer a death sentence. Instead, it is a chronic, long-term disease (1). Before 1995, a newly infected person faced the near-certainty of dying with AIDS. Today a newly infected person can look forward to 24 years and potentially much more! of living with HIV (3). Very few pregnant women with HIV/AIDS pass on the disease to their unborn children. Without HIV treatment, one in four pregnant women with HIV or AIDS transmits the virus to their babies (4). The CDC reports that in 1992, 885 children developed AIDS; in 2005, that number decreased to 57 children a 93 percent decline (5).

Although the HIV good news is an honor, yet some of the obstacles threats eradication and struggle of this disease. Despite many treatment and prevention successes to combat the HIV epidemic, people are still dying from AIDS. In 2006, HIV was the third leading cause of death for black men and women 35 to 44 years old and the fourth leading cause of death for Latino men and women of the same age (6). From the start of the HIV epidemic through 2007, more than 576,000 people in the United States have died from AIDS (5). For instance, the incidence of HIV among youth and young adults between 12 and 24 years of age has increased over the past five years, while other populations have experienced a decline in their rates of infection (5). The increase is probably related to a combination of increased testing, lack of awareness of HIV status, continued high-risk behaviors, and some disinhibition regarding the potential risks and implications of an HIV diagnosis (7). It is estimated that $50 \%$ of persons with HIV acquired the in- fection during their adolescent or youth years, presenting to care later (7). Men having sex with men (MSM) make up only 2 percent of the United States population, but they accounted for 61 percent of all new HIV infections in 2009. Men who have sex with other men report higher rates of condom use and HIV testing than other groups, but they still have the highest rates of infection (8).

Overall, there is plenty of reason to celebrate the achievements of the last 33 years of success, and plenty of hope for the future. Also there is optimism around the possibility of a genuine cure for HIV being developed within the next few decades. Also, the launch of a new strategy to develop a cure, involving scientists, policy makers, funders and people living with HIV seems highly vital.

\section{Acknowledgements}

The author of this article thanks Miss Bita Pourkaveh for her contribution in collecting data and writing paper.

\section{References}

1. Deeks S. Towards an HIV cure. J Int AIDS Soc. 2014;17(4 Suppl 3):19479.

2. Santelli JS, Edelstein ZR, Wei Y, Mathur S, Song X, Schuyler A, et al. Trends in HIV acquisition, risk factors and prevention policies among youth in Uganda, 1999-2011. AIDS. 2015;29(2):211-9.

3. Viard JP. [Comorbidities in HIV infection and aging with HIV ]. Rev Prat. 2014;64(8):1086-90.

4. Kabami J, Turyakira E, Biraro S, Bajunirwe F. Increasing incidence of pregnancy among women receiving HIV care and treatment at a large urban facility in western Uganda. Reprod Health. 2014;11:81.

5. Centers for Disease Control and Prevention: CDC; Available from: WWW.CDC.COM.

6. Meng B, Lever AM. Wrapping up the bad news: HIV assembly and release. Retrovirology. 2013;10:5.

7. Kenu E, Obo-Akwa A, Nuamah GB, Brefo A, Sam M, Lartey M. Knowledge and disclosure of HIV status among adolescents and young adults attending an adolescent HIV clinic in Accra, Ghana. BMC Res Notes. 2014;7:844.

8. Jones J, Stephenson R, Smith DK, Toledo L, La Pointe A, Taussig J, et al. Acceptability and willingness among men who have sex with men (MSM) to use a tablet-based HIV risk assessment in a clinical setting. Springerplus. 2014;3(2):708.

Copyright ( 2014 , Infectious Diseases and Tropical Medicine Research Center; Published by Kowsar. This is an open-access article distributed under the terms of the Creative Commons Attribution-NonCommercial 4.0 International License (http://creativecommons.org/licenses/by-nc/4.0/) which permits copy and redistribute the material just in noncommercial usages, provided the original work is properly cited. 